\title{
Correction to: Four novel interaction partners demonstrate diverse modulatory effects on voltage-gated $\mathrm{Cav}_{\mathrm{v}} 2.2 \mathrm{Ca}^{2+}$ channels
}

\author{
Robert Mallmann ${ }^{1} \cdot$ Katarina Ondacova ${ }^{2}$ - Lucia Moravcikova ${ }^{2} \cdot$ Bohumila Jurkovicova-Tarabova $^{2}$. \\ Michaela Pavlovicova ${ }^{2} \cdot$ Roman Moravcik $^{2} \cdot$ Lucia Lichvarova $^{2} \cdot$ Viera Kominkova $^{2}$ - Norbert Klugbauer ${ }^{1}$. \\ Lubica Lacinova ${ }^{2}$
}

Published online: 22 February 2019

(C) Springer-Verlag GmbH Germany, part of Springer Nature 2019

Correction to: Pflügers Archiv - European Journal of Physiology 2018

https://doi.org/10.1007/s00424-018-02248-x

The article was originally published with one author missing. The name of the co-author Roman Moravcik was inadvertently omitted. His name and affiliation have now been added to the author list. The original article has been corrected.

Publisher's note Springer Nature remains neutral with regard to jurisdictional claims in published maps and institutional affiliations.

The online version of the original article can be found at https://doi.org/ $10.1007 / \mathrm{s} 00424-018-02248-\mathrm{x}$

Lubica Lacinova

lubica.lacinova@savba.sk

1 Institut für Experimentelle und Klinische Pharmakologie und Toxikologie, Fakultät für Medizin, Albert-Ludwigs-Universität, Freiburg, Albertstr. 25, 79104 Freiburg, Germany

2 Center of Bioscience, Institute for Molecular Physiology and Genetics, 84005 Bratislava, Slovakia 